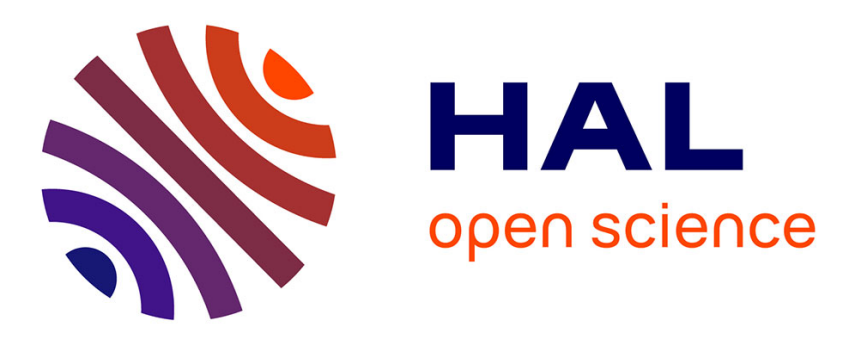

\title{
An Integrated Bayesian Network Approach to Bloom Initiation
}

\author{
Sandra Johnson, Fiona Fielding, Grant Hamilton, Kerrie Mengersen
}

\section{To cite this version:}

Sandra Johnson, Fiona Fielding, Grant Hamilton, Kerrie Mengersen. An Integrated Bayesian Network Approach to Bloom Initiation. Marine Environmental Research, 2009, 69 (1), pp.27. 10.1016/j.marenvres.2009.07.004 . hal-00563092

\section{HAL Id: hal-00563092 https://hal.science/hal-00563092}

Submitted on 4 Feb 2011

HAL is a multi-disciplinary open access archive for the deposit and dissemination of scientific research documents, whether they are published or not. The documents may come from teaching and research institutions in France or abroad, or from public or private research centers.
L'archive ouverte pluridisciplinaire HAL, est destinée au dépôt et à la diffusion de documents scientifiques de niveau recherche, publiés ou non, émanant des établissements d'enseignement et de recherche français ou étrangers, des laboratoires publics ou privés. 


\section{Accepted Manuscript}

An Integrated Bayesian Network Approach to Lyngbya majuscula Bloom Initiation

Sandra Johnson, Fiona Fielding, Grant Hamilton, Kerrie Mengersen

PII:

S0141-1136(09)00103-2

DOI:

10.1016/j.marenvres.2009.07.004

Reference:

MERE 3360

To appear in:

Marine Environmental Research

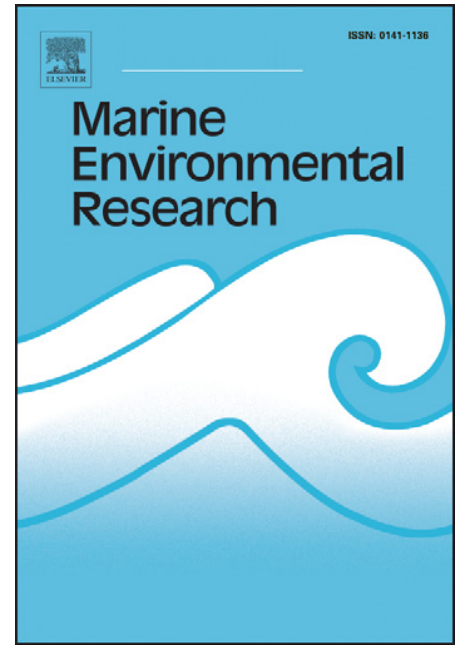

Received Date: $\quad 15$ January 2009

Revised Date: $\quad 25$ July 2009

Accepted Date: $\quad 28$ July 2009

Please cite this article as: Johnson, S., Fielding, F., Hamilton, G., Mengersen, K., An Integrated Bayesian Network Approach to Lyngbya majuscula Bloom Initiation, Marine Environmental Research (2009), doi: 10.1016/ j.marenvres.2009.07.004

This is a PDF file of an unedited manuscript that has been accepted for publication. As a service to our customers we are providing this early version of the manuscript. The manuscript will undergo copyediting, typesetting, and review of the resulting proof before it is published in its final form. Please note that during the production process errors may be discovered which could affect the content, and all legal disclaimers that apply to the journal pertain. 


\section{An Integrated Bayesian Network Approach to}

\section{Lyngbya majuscula Bloom Initiation}

3

4 Sandra Johnson*, Fiona Fielding, Grant Hamilton, Kerrie Mengersen 5

9 *Corresponding author: Sandra Johnson, School of Mathematical Sciences,

School of Mathematical Sciences, Queensland University of Technology, GPO Box 2434, Brisbane, QLD 4001, Australia Queensland University of Technology, GPO Box 2434, Brisbane, QLD 4001, Australia

Email: sandra.johnson@qut.edu.au

Tel: +61 (0)7 3138 1292, Fax: +61 (0)73138 2310

\section{Abstract}

Blooms of the cyanobacteria Lyngbya majuscula have occurred for decades around the world. However, with the increase in size and frequency of these blooms, coupled with the toxicity of such algae and their increased biomass, they have become substantial environmental and health issues. It is therefore imperative to develop a better understanding of the scientific and management factors impacting on Lyngbya bloom initiation. This paper suggests an Integrated Bayesian Network (IBN) approach that facilitates the merger of the research being conducted by various parties on Lyngbya.

4 Pivotal to this approach are two Bayesian networks modelling the 
25

management and scientific factors of bloom initiation. The research found that Bayesian networks (BN) and specifically Object Oriented BNs (OOBN) and Dynamic OOBNs facilitate an integrated approach to modelling ecological issues of concern. The merger of multiple models which explore different aspects of the problem through an IBN approach can apply to many multifaceted environmental problems.

Keywords: Bayesian network, cyanobacteria, DOOBN, dynamic, IBN, Lyngbya majuscula, object oriented, OOBN.

\section{Introduction}

Lyngbya majuscula is a cyanobacterium (blue-green algae) occurring naturally in tropical and subtropical coastal areas worldwide (Osborne et al., 2001; Arquitt and Johnstone, 2004; Dennison et al., 1999), including Moreton Bay in Queensland, Australia. Lyngbya grows on the sediment or over the seagrass, algae or coral (Dennison and Abal, 1999; Watkinson et al., 2005) and when the conditions are favourable, the algae goes through a rapid growth phase, resulting in a substantial increase in biomass, commonly referred to as a bloom (Ahern et al., 2007; Hamilton et al., 2007c). Lyngbya blooms appear to be increasing in both frequency and extent (Dennison and Abal, 1999; Albert et al., 2005; Ahern et al., 2007), which can have major ecological (Stielow and Ballantine, 2003; Paul et al., 2005; Watkinson et al., 2005), health (Osborne et al., 2001; Osborne et al., 2007) and economic consequences (Dennison and Abal, 1999). It is therefore imperative to better 
understand the scientific and management factors that drive the initiation of $L$. majuscula blooms.

Deception Bay, located in Northern Moreton Bay in Queensland, Australia, has a history of Lyngbya blooms (Watkinson et al., 2005; Ahern et al., 2007) and forms a case study for this investigation. With its proximity to Brisbane, Australia's third largest city with an estimated population in 2004 of 1.78 million (ABS, 2004), it is a popular tourist destination. The many waterways feeding from intensive and rural agricultural activities into the Bay and its use for commercial and recreational fishing, put pressure on the marine environment and compound the issues resulting from a nuisance algal bloom (Dennison and Abal, 1999).

A modelling approach was required to identify the high priority research that needed to be undertaken into the poorly known features of Lyngbya initiation. Therefore it was necessary to capture and represent all the available data and expert knowledge about the initiation of Lyngbya blooms in Deception Bay. This approach had to engage stakeholders, represent the available information at different spatial and temporal scales, identify scientific and management factors affecting Lyngbya initiation and quantify the factors and their inter-dependencies. Moreover, the stakeholders were particularly diverse comprising ecologists and scientists familiar with Lyngbya and the factors that affect its bloom, state and local government representatives, committee members of local organisations, as well as individuals with an active interest 
72 in Lyngbya, including a third generation local fisherman with decades of

73 accumulated knowledge of Lyngbya blooms in the Bay.

74

75 There are several modelling approaches that could be considered for such a 76 problem, including decision trees, stochastic petri nets and Bayesian 77 networks. A decision tree has a "top-down approach". The first factor (root 78 node) at the top of the tree is split according to the decision taken. Each 79 subsequent node is then split in a similar way (Janssens et al., 2006). This 80 approach lacked the ability to represent the many interactions between the

81 factors which would be needed to model the initiation of a Lyngbya bloom. A 82 stochastic petri net (SPN), also known as a place/transition net is used to 83 model concurrent systems (Angeli et al., 2007). Implementing a SPN is not 84 trivial, even with the use of bespoke software. It mandates some statistical 85 knowledge as well as some familiarity with stochastic process theory and Monte Carlo simulation techniques (Goss and Peccoud, 1998). A Bayesian

87 Network (BN) provides a graphical representation of key factors, which are represented as nodes in the diagram and their causal relationships with each other and with the outcome of interest (Borsuk et al., 2006; McCann et al.,

90 2006; Jensen and Nielsen, 2007; Uusitalo, 2007) are depicted as directed 91 links or arrows connecting a 'parent node' to a 'child node', resulting in a 92 directed acyclic graph (DAG) (Saddo et al., 2005; Jensen and Nielsen, 2007; 93 Uusitalo, 2007; Park and Stenstrom, 2008). BNs are better able to portray the 94 complexity of the decision process and the many inter-dependencies between 95 the factors of the decision process (Janssens et al., 2006). Moreover, they are 96 visually appealing, easy to use, comprehend and interact with. For more 
97 detailed information about the advantages and disadvantages of BNs and 98 comparisons with alternative statistical methods, we refer the reader to 99 (Wilson et al., 2006; Uusitalo, 2007; Ahmed et al., 2009).

100

101 Bayesian networks have been used successfully to better understand and

102 model many complex environmental problems (Bromley et al., 2005). They

103 facilitate the representation of different management decisions and scenarios

104 that may impact on the environmental issue being modelled and the 105 consequences of these situations and actions (McCann et al., 2006; Uusitalo,

106 2007). However, the focus of many networks is often on a single aspect of the

107 outcome, and multi-faceted inferential needs are most commonly addressed

108 through multiple independent networks. This paper describes an approach to

109 integrating diverse knowledge about Lyngbya bloom initiation in the Deception

110 Bay area, by developing an Integrated Bayesian Network (IBN). The IBN

111 comprises a series of BNs designed to conceptualize and quantify the major

112 factors and their pathways contributing to the initiation of Lyngbya, from both

113 scientific and management perspectives. In Figure 1 a unified modelling

114 language (UML) use case diagram illustrates the conceptual processes of the

115 Lyngbya IBN. To our knowledge an IBN approach has not previously been

116 applied to Lyngbya bloom initiation.

\section{7}

118

119

120 In Section 2 we describe the characteristics of a traditional BN, an object

121 oriented $\mathrm{BN}(\mathrm{OOBN})$ and the natural progression to a dynamic OOBN 
122 (DOOBN). We then introduce the integrated BN approach (IBN) which

123 consolidates the information held in various networks and models. We present

124 the results of this approach in Section 3 by applying it to the initiation of 125 Lyngbya blooms.

126

\section{$127 \quad 2$ Methods}

\section{$128 \quad 2.1$ Bayesian Network (BN)}

129 As described in Section 1, a BN visualizes knowledge about an ecological 130 issue of interest with the important factors depicted as nodes in the network.

131 These nodes may be at different temporal and spatial scales and the data 132 represented in the $\mathrm{BN}$ may originate from diverse sources such as empirical 133 data, expert opinion and simulation outputs (Saddo et al., 2005; Borsuk et al.,

134 2006; McCann et al., 2006; Jensen and Nielsen, 2007; Pollino et al., 2007;

135 Park and Stenstrom, 2008). In the case of the Lyngbya network, the outcome

136 of interest is the initiation of a Lyngbya bloom. Each node of the network is 137 described by a set of states (for example high/medium/low,

138 adequate/inadequate) and quantified by associating a probability table with

139 each node. The probability table is determined by these states and the states

140 of the nodes that influence it. An example is the conditional probability table 141 (CPT) for the Bottom Current Climate node, shown in Table 1, which has two 142 states (Low and High) and has three parent nodes that influence it (Wind 143 Direction, Wind Speed and Tide) (Saddo et al., 2005; Pollino et al., 2007; Park 144 and Stenstrom, 2008). 
148 Two important characteristics of a BN which also simplify probability 149 calculations are directional separation (d-separation) and the assumption of 150 the Markov property (Jensen and Nielsen, 2007). The criterion for $d$ 151 separation was first proposed by (Pearl, 1988) and an alternative criterion was 152 specified by Lauritzen et al., (1990). If nodes are d-separated then they are 153 conditionally independent (Kjaerulff, 1995, Taroni et al., 2006). The Markov

154 property means that the probability distribution of a variable depends only on

155 its parents. Consequently from the multiplication law of elementary probability 156 theory, the conditional independence (d-separation) and the Markov property 157 enable the probability distribution of a BN with $n$ nodes $\left(X_{1}, \ldots X_{n}\right)$ to be 158 factorized as follows:

$159 P\left(X_{1}, \ldots X_{n}\right)=\prod_{i=1}^{n} P\left(X_{i} / P a\left(X_{i}\right)\right) \quad$ where $P a\left(X_{i}\right)$ is the set of parents of node $X_{i}$

160 This greatly simplifies calculations of the joint probability distribution and

161 allows us to focus on each node in turn to combine the expertise and data

162 available for that node and its parents. The BNs described in this paper were

163 developed as part of a larger study of the major factors and their pathways 164 contributing to the initiation of Lyngbya blooms. They were constructed in 165 close collaboration with a Lyngbya Science Working Group (LSWG) drawn 166 from a range of disciplines and a Lyngbya Management Working Group

167 (LMWG) drawn from local and state government and private organisations 168 (Abal et al., 2005). 
170 The Science Network focused on nutrient and physical factors that were

171 agreed by the LSWG to be the most influential contributors to the initiation of

172 Lyngbya. To construct the Science Network, numerous meetings were

173 convened to determine the most important factors that were believed to have

174 an impact on the ecosystem surrounding Deception Bay. Once the initial

175 structure was agreed upon, the factors were then clearly defined. This was

176 necessary to ensure throughout the process all involved could refer to these

177 definitions to agree that this was indeed the focus of that particular aspect.

178 The initial Lyngbya Science BN was then colour coded into six logical groups

179 of coherent nodes. The groups are Water (containing nodes Rain-present, No

180 prev dry days, Groundwater Amount and Land Run-off Load), Sea Water

181 (containing Tide, Turbidity and Bottom Current Climate), Air (containing nodes

182 Wind and Wind Speed), Light (containing nodes Light Quantity, Light Quality

183 and Light Climate), Nutrients (containing nodes Dissolved Fe Concentration,

184 Dissolved Organics, Dissolved N Concentration, Dissolved P Concentration,

185 Particulates (Nutrients), Sediments Nutrient Climate, Point Sources and

186 Available Nutrient Pool), and Lyngbya Algae (containing only the target node

187 Bloom Initiation).

189 Thereafter the network was quantified by populating a conditional probability 190 table for each node, based on the factors affecting that node. For example, 191 the probability of low or high Bottom Current Climate was determined for

192 different states of its parent nodes, Wind Direction (north, south-east or other),

193 Wind Speed (low or high) and Tide (spring or neap), as shown in Table 1. The

194 CPTs were populated in this way using data obtained from expert elicitation, 
195 output from simulation models and statistical models and data obtained from

196 monitoring sites and government agencies. The datasets spanned different

197 time periods ranging from one season to several years, depending on

198 availability and applicability. Meta-data on these datasets were compiled as a

199 key component of the project. The meta-database, comprising the source,

200 ownership, type of data and dates collected, is summarised in a Healthy

201 Waterways report (Fielding et al., 2007), and is available on the organisation's

202 website.

203

204 Validation of the BN was assessed in three ways: through sensitivity analysis,

205 outcomes comparison and scenario testing. Sensitivity analysis is a popular

206 technique in mathematical modelling and the field of decision theory to 207 investigate uncertainty in a model's parameters and their effect on the model 208 output (Hamby, 1994; Coupe et al., 2000). For BNs this means studying the 209 changes in the probabilities of the target node as a result of changes in the 210 network's CPT values (Coupe et al., 2000). In the Science BN the 211 probabilities of one node was varied, while keeping the others fixed, and then 212 observing the changes in the probability of a Lyngbya bloom initiation.

213 Sensitivity analysis is considered crucial to model validation and for targeting 214 further research (Hamby, 1994). It is performed on the BN model to reduce 215 uncertainty in the target node and to identify those nodes that have the largest 216 impact on the target node (Hamby, 1994; Coupe et al., 2000). Additional 217 research effort can then be directed to the quantification of those nodes 218 (Bednarski et al., 2004). 
220 Outcomes comparison involves comparison between external data and model 221 predictions. In the case of the Lyngyba Science BN, no such external data 222 were available since all known available data had been used to populate 223 aspects of the BN. Moreover, for any observed Lyngbya outbreak, data were 224 not available for the complete set of nodes in the BN model. As a result, a 225 more limited outcomes comparison was undertaken through scenario testing, 226 in which selected scenarios reflected known conditions associated with 227 documented initiation or lack of initiation of Lyngbya outbreaks in the last 30 228 years.

230 Scenario testing is important to investigate model behaviour for different 231 expert defined scenarios, assessing whether the model behaves as expected 232 in light of past experience and in accordance with current credible research 233 (Laskey, 1995; Bednarski et al., 2004). The expert team therefore nominated 234 scenarios of interest and evidence was entered into the BN to represent these 235 scenarios. The relevant nodes were updated to reflect the proposed scenario 236 and this evidence was propagated through the BN to update the probability of 237 a Lyngbya bloom initiation under those conditions (Laskey, 1995; Bednarski et 238 al., 2004). For example, evidence of 'best practice' was entered into the BN 239 by setting the Point sources node to low. Further sensitivity analysis was then 240 performed on the other nodes in the BN to observe the sensitivity of the target 241 node to changes in node probabilities for that scenario.

243 The Management Network focused on management inputs that potentially 244 influence the delivery of nutrients to the Bay and was constructed through a 
245

246

247

248

265 The definition of classes of objects in OOBNs enables a more generic, 266 reusable network to be described, which can then be used in different 267 contexts. A class is a generic network fragment and when this class is 268 instantiated it is called an object. A class may be instantiated many times 269 (Jensen and Nielsen, 2007). It is not uncommon for several classes to share 
270 common substructures. These subclasses can inherit many attributes and

271 behaviours from the parent class, which they can then modify and enhance.

272 The parent class can be viewed as being more abstract than its subclasses

273 with only the important details being retained, whereas subclasses define

274 more specific attributes and behaviours. The ability to create subclasses that

275 inherit properties from another class is a well known and very useful

276 characteristic of object oriented modelling (Koller and Pfeffer, 1997).

277

278 Applying this object oriented approach to BN modelling, an OOBN can be 279 instantiated within another OOBN. An instantiated OOBN is called an instance 280 node and represents an instance of another network, which in turn could 281 contain instance nodes. Connectivity between these OOBNs is achieved 282 through interface nodes (input nodes and/or output nodes) (Hugin, 2007; 283 Jensen and Nielsen, 2007). It is clear that OOBNs enable a more structured, 284 hierarchical approach to modelling and consequently the construction of 285 complex and dynamic models (Koller and Pfeffer, 1997; Hepler and Weir, 286 2008).

288 The groups of nodes defined in Section 2.1 for the Science Network formed 289 the basis for the creation of OOBN sub-networks, for example the 'Dissolved 290 Elements subnet' and 'Light subnet', respectively. Thereafter the interface 291 nodes were identified and added to the sub-networks to facilitate the transfer 292 of information and evidence into and out of the sub-nets. The OOBN sub293 networks were then linked via the interface nodes to recreate the Lyngbya 294 Science network. The new structure now facilitated the independent parallel 
295 development and interrogation of the sub-networks so that they could be

296 reintegrated into the parent network when they were deemed to be complete.

297

298

299

300

301

302

303

304

305

306

307

308

\subsection{Dynamic Object Oriented Bayesian Network (DOOBN)}

The temporal behaviour of a network can be represented by time slices, one for each period of interest. The resulting network, consisting of several OOBN time slices, is referred to as a dynamic OOBN (DOOBN) (Kjaerulff, 1995; Weber and Jouffe, 2006). Lyngbya blooms in Moreton Bay occur more frequently during the summer months when conditions are more favourable for bloom initiation (Watkinson et al., 2005). Additional statistical modelling was conducted by Hamilton et al. (2007a) on the effects of temperature, rainfall and light on $L$.majuscula blooms and the importance of groundwater in stimulating Lyngbya blooms has been studied by (Ahern et al., 2006) and was nominated by LSWG as a key node that may exhibit temporal behaviour. It was thus considered that the DOOBN would be better able to predict the probability of Lyngbya bloom initiation. A UML use case diagram illustrating the processes involved in creating this DOOBN, is shown in figure 2.

\section{(Place Figure 2 here)}

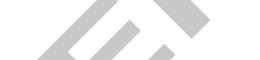

The initial static Science BN model used annual averages for rainfall and temperature, but captured some temporal behaviour by introducing a node to represent the previous number of dry days. As directed by the LSWG the Lyngbya Science BN was extended to incorporate the temporal nature of $L$. majuscula to create a DOOBN with five time slices (one for each of the months of November to March). The DOOBN is therefore able to predict the 
320

321

probability of a Lyngbya bloom initiation by incorporating specific monthly data while also taking into account the influence of the previous month.

Using Bayesian statistical modelling (Hamilton et al., 2007b) investigated the response of Lyngbya bloom initiation to temporal factors such as average minimum and maximum monthly temperature, monthly rainfall, average monthly solar exposure and average monthly clear sky (the inverse of cloud cover). One month time lags and interaction terms were also included for rain and minimum temperature. From a total of 890 models evaluated, the single term average minimum monthly temperature model (with an intercept term) had the best predictive behaviour. Rainfall at a lag of one month was the only other variable that appeared in the top five identified models.

\subsection{Integrated Bayesian Network (IBN)}

We describe here the IBN for the probability of initiation of a Lyngbya bloom. This network comprises two primary BNs, the Management Network and the Science Network described in Section 2.1, integrated with a Water Catchment simulation model, which was concurrently developed under the Lyngbya Programme. The IBN is conceived as a series of steps, in which the Management Network informs about nutrient discharge into the Deception Bay catchment, the Catchment model simulates the movement of these nutrients to the Lyngbya site in the Bay, and the Science model then integrates this nutrient information with other factors to determine the probability of initiation of a Lyngbya bloom. 
345 Figure 3 is a UML activity diagram detailing the processes of the IBN for

346 Lyngbya bloom initiation. In addition to providing a rich, cohesive model of

347 Lyngbya bloom initiation from both a science and management perspectives,

348 an important use of the IBN was for scenario modelling. A set of exemplar

349 scenarios that could impact on nutrient delivery to the Lyngbya site was

350 proposed. This included: upgrading point sources from existing to best

351 practice (e.g. eliminating potassium output from sewage treatment plants

352 across the catchment), describing a climate event (e.g. a severe summer

353 storm), and conditions least favourable for bloom initiation (e.g. low

354 temperature and nutrients).

356 For each proposed scenario the changes in the level of nutrients or to the

357 factors affecting the initiation of Lyngbya in the Science network were 358 assessed. If nutrient loads were changed, the impact on nutrient 359 concentrations across the catchment arising from a management scenario 360 could then be simulated through the Water Catchment model by the 361 application of filters. The E2 software package (eWater CRC, 2007) used to 362 create the Water Catchment model contains several pre-defined filters 363 capable of simulating various complex management actions and adjusting the 364 catchment load output accordingly. For example filters such as percentage 365 removal of a nutrient and nutrient trapping may be chosen. Thereafter the 366 Science Network was updated to reflect the modified nutrient loads and other 367 changes related to the proposed scenario. This evidence was then 368 propagated through the network to yield the probability of initiation of a 369 Lyngbya bloom under the specific scenario. 
373 The networks in the IBN were developed using a variety of software modelling

374 tools. The conceptual Management Network was visually represented using

375 the BN package Netica® (Norsys, 2007) and then interfaced with the 376 hydrological flow and nutrient load model created in the whole of catchment 377 simulation software package, E2 (eWater CRC, 2007), in order to identify 378 nutrient loads reaching the Lyngbya site. The Science Network was 379 developed entirely in Netica ${ }^{\circledR}$ and later in Hugin® (Hugin, 2007) where the 380 network was transformed into a DOOBN by creating time slices (Kjaerulff, 381 1995; Weber and Jouffe, 2006; Jensen and Nielsen, 2007). In summary, the 382 novelty factor here is that although a static BN is unable to 'communicate' with 383 another $\mathrm{BN}$, we can transform it to an OOBN to facilitate information flow and 384 linkage to other OOBNs of interest. Thus we can exploit the purpose for which 385 each model was designed to build a more comprehensive model of the 386 environmental issue of concern.

\section{Results}

389 The static Science BN for initiation of Lyngbya is depicted in figure 4 with the 390 nodes representing the factors identified by the LSWG as important in the 391 initiation of a Lyngbya bloom. 
395 Sensitivity analysis of this BN revealed that the seven most influential factors

396 in the Science Network were (in decreasing order of influence): available

397 nutrient pool (dissolved), bottom current climate, sediment nutrients, dissolved

398 iron (Fe), dissolved phosphorous $(\mathrm{P})$, light and temperature. Furthermore

399 scenario modelling consistently identified available nutrient pool as the factor

400 which most heavily influences the probability of initiation of a bloom. Point and

401 diffuse sources deliver nutrients to the bay and this nutrient delivery is

402 affected by management actions at the sources.

403

404 The Science BN was also interrogated using management and climatic 405 scenarios and analysing the effect on the probability of bloom initiation to 406 changes in the various factors. The predicted changes in the probability of a 407 Lyngbya bloom initiation as a result of each of the seven most influential 408 factors in isolation, is shown in Table 2. In a 'typical' year, as defined by the 409 LMWG, the probability of a bloom initiation was reported as $28 \%$; this 410 increased significantly during a severe summer storm event to $42 \%$, when 411 light climate was optimal and rain-present was high. Bloom initiation was a 412 predicted as a certainty (100\%) when the available nutrient pool (dissolved) 413 was enough, temperature was high and light climate was optimal. However, 414 when only the available nutrient pool (dissolved) was set to 'not enough', the 415 probability of a bloom initiation dropped to $3 \%$, but jumped to $80 \%$ when it 416 was changed to 'enough'. Although bottom current climate was a key 417 influential factor, changing only this factor caused the probability of bloom 418 initiation to drop to $15 \%$ when the bottom current climate was 'high' and to 419 increase to $43 \%$ when it was 'low'. This is a variation of $28 \%$ in the probability 
420 of a bloom initiation and although large, is clearly overshadowed by the $77 \%$

421 variation caused by changes in nutrient availability. Changing iron availability

422 alone increased the probability of a bloom initiation from $21 \%$ to $37 \%$.

423 Changing organics availability alone increased the probability of a bloom 424 initiation from $25 \%$ to $31 \%$.

(Place Table 2 here)

428 Next the Science OOBN sub-network (figure 5) was created from the static 429 Lyngbya Science BN as outlined in Section 2.2, retaining all the key factors 430 (with the exception of the No of prev dry days) and their CPTs from the static 431 BN. As is characteristic of Object Oriented networks, the Science OOBN sub432 network includes instances of other sub-networks, shown in figure 5 as 433 rectangles with rounded edges, such as the Wind subnet and the Turbidity 434 subnet. Input nodes were added to the Science OOBN sub-network as 435 placeholders for the real nodes, Temperature, Rain- present, Land Run-off 436 Load and Ground Water Amount. The sub-networks were based on the 437 groups created in the static Science BN to yield standalone networks capable 438 of linking to other networks via the interface nodes (input and output nodes), 439 or being instantiated in other networks. Importantly, providing the interface 440 remains intact, these OOBN sub-networks can be further expanded without 441 affecting the structure of any other networks linking to it. As a consequence 442 we have a powerful concept of parallel development by independent expert 443 teams while retaining the overall cohesive model. 
447 In collaboration with the LSWG and based on the findings of (Hamilton et al., 448 2007a) as described in Section 2.3, the static Lyngbya Science network was 449 adapted in the following manner to incorporate monthly rainfall and 450 temperature data and the lag effect of rainfall on the amount of groundwater 451 and land run-off. First, the lag effect of rainfall on groundwater amount and 452 land run-off was replicated by creating a Rainwater OOBN sub-network as 453 shown in figure 6. In this OOBN, the Prev Groundwater and the Prev Land 454 Run-off are input nodes (double edged eclipse with a broken outer line), which 455 enable connectivity to the previous time slice's Ground Water Amount and 456 Land Run-off nodes, respectively. The Rain - present input node enables the 457 instances of the Rainwater OOBN to be bound to the rainfall relating to that 458 instance, e.g. the November Rainwater OOBN instance will have November's 459 rainfall bound to the Rain - present input node. The Ground Water Amount 460 and Land Run-off Load output nodes (double edged eclipse with a solid outer 461 line) make them visible to other networks and therefore allow them to be 462 bound to input nodes in other networks.

466 Finally the DOOBN was created with five time slices (figure 7), one time slice 467 for each of the summer months (December to February), one for the end of 468 spring (November) and one for the start of autumn (March). Every time slice 469 has an instance of the Rainwater and Science sub-networks as well as the 
470 temperature and rainfall nodes for that month. Data from the Bureau of

471 Meteorology was used to quantify the DOOBN, as well as the information 472 contained in the initial static BN.

473

474

(Place Figure 7 here)

475

476 As can be seen in figure 8, the rainfall information for a particular month is

477 bound to the Rain present input node in the Rainwater and Science model

478 sub-network instances for that month and the Groundwater Amount and Land

479 Run-off output nodes from one month bind to the Prev Groundwater and Prev

480 Land Run-off input nodes of the following month, respectively.

481

484 The point and diffuse nutrient sources contributing to the Management

485 Network for Lyngbya initiation included: aquaculture, composting, onsite 486 487 488 489

491 An extract of the Management Network, which identifies and locates point and

492 diffuse sources of nutrients for the Mellum Creek Sub-catchment, visually 493 represented in $\mathrm{Netica} \AA$, is shown in figure 9. 
496

497 Scenario modelling predicted higher probabilities of Lyngbya bloom initiation 498 during the summer months and confirmed the temporal nature of Lyngbya 499 bloom initiation. Incorporating this behaviour resulted in the DOOBN for 500 Lyngbya bloom initiation (figure 7) being developed as outlined above with 501 one month lag effects included for groundwater amount and land run-off.

502

503 As shown in figure 10 below, the BN predicts a sharp increase in the 504 probability of initiation of a Lyngbya bloom from the end of spring (November) 505 to the first month of summer (December). The increased probability continued 506 during the next two summer months, with a slight fall in autumn (March). 507 Although these predicted probabilities for Lyngbya bloom initiation are low, the 508 increased trend in bloom initiation is clearly visible. When evidence of summer 509 rainfall was added to these time slices we observed a more dramatic 510 increase. For example, the probability of a bloom initiation was predicted as $51152 \%$ when evidence of a summer rainfall event was entered into the 512 December time slice. This compares to $42 \%$ in the original static annual BN 513 model. (Place Figure 10 here)

\section{Discussion}

518 This paper describes an Integrated Bayesian Network approach applied to the 519 initiation of Lyngbya blooms. The aim was to present the exposition of BN 
520 methodology to a complex ecological problem such as Lyngbya bloom

521 initiation and illustrate how it can be used to integrate models for different

522 aspects of the same issue. We have illustrated the process that could be 523 followed to integrate two static BNs and another type of model (such as the

524 E2 model of the Whole of Catchment) to achieve an integrated BN. The IBN 525 approach described here can also be used for investigating other features of 526 this organism, such as growth, biomass and decay, through appropriate 527 changes to the Science Network. These networks are currently being 528 developed. The Integrated Network approach is also conceptually suitable for 529 investigating other outcomes of interest that are impacted by nutrient outputs 530 and water movement in a catchment.

532 It is noted that it is beyond the scope of the present paper to provide an actual 533 test of the utility of BNs for predicting cyanobacterial blooms. The paper 534 therefore does not include a comparison of the predictions against classical 535 multivariate techniques; a test of the BNs own output reliability, that is, 536 whether the probabilistic estimate of the likelihood the BNs output is correct 537 for the target data set; a clear presentation of exactly what data are being 538 used; a sufficient amount of data to first build and refine the model on one 539 data set and then test it on a previously unseen set of data. However the 540 Science BN, which has been adopted by Healthy Waterways, will be validated 541 through future data collected as part of the next phase of the Lyngbya project.

543 More broadly, the general approach proposed in this paper is applicable to 544 environmental or other outcomes involving both scientific and management 
545 considerations. Information arising from expert knowledge, data and research

546 can be formally conceptualized and quantified through Science and

547 Management Networks, and combined into an Integrated Network. Such an

548 approach involves definition of the problem or outcome of interest, agreement

549 as to significant contributing factors and their definitions and pathways which

550 impact on this outcome, and identification and integration of information that

551 allow quantification of these factors and impacts. The benefits of such an

552 approach include a much greater specification of the issue at hand or

553 research focus, buy-in from diverse stakeholders, consolidation and

554 formalisation of information, an audit trail for decision-making and future

555 research, and quantitative outcomes in the form of probability statements

556 about the outcome of interest.

557

558 In the static Lyngbya BN (figure 4) similar factors were grouped together and

559 colour coded as a visual aid. The nature of the Science BN enabled a simple

560 conversion of the network to an OOBN (figure 6), with a sub-network for each

561 group of factors and interface nodes providing the communication links to

562 other OOBNs (figure 8). In the same way many complex BNs can be

563 simplified by abstracting the network to a higher level to include sub-networks

564 of logically grouped factors, which in turn can include other sub-networks,

565 thereby having several levels of abstraction. An important feature of the

566 OOBN sub-networks is that they can be developed simultaneously by the

567 various expert groups who are responsible for them. When the sub-networks

568 have been quantified, tested and ratified, they are integrated into the master

569 network containing instances of those sub-networks. 
571 The extension to a DOOBN not only improved prediction but also enhanced

572 interpretability of the network. The inclusion of time-specific dynamics for

573 temperature and water was more consistent with the conceptual framework of

574 Lyngbya behaviour held by both science and management stakeholders.

575 Moreover, it is more straightforward to include expert opinion and data of a

576 temporal nature in this expanded model. It is suggested that for other complex

577 ecological systems, the additional complexity of a DOOBN is more than

578 compensated for by the increased flexibility of representation of information 579 and acceptability of the outputs.

581 Finally, the creation of an IBN to combine multiple networks which describe 582 different aspects of an outcome of interest is an effective way of providing a 583 cohesive, quantifiable and auditable tool for better understanding and 584 coordination of multi-faceted environmental problems.

\section{Acknowledgements}

587 Financial assistance was provided by the Environmental Protection Agency 588 and Australian Government through the South East Queensland Healthy 589 Waterways Partnership, the ARC Centre for Dynamic Systems and Control, 590 and QUT Institute for Sustainable Resources. We fully acknowledge the 591 contributions of the Lyngbya Management Working Group and the Lyngbya 592 Science Working Group. For helpful comments on the manuscript we 593 acknowledge Kathleen Ahern, Barry Hart and an anonymous reviewer. 
595

596

597

598

599

600

601

602

603

604

605

606

607

608

609

610

611

612

613

615

616

617

\section{References}

Abal E G, Greenfield P F, Bunn S E and Tarte D M 2005 Healthy Waterways: Healthy Catchments - An Integrated Research/Management Program to Understand and Reduce Impacts of Sediments and Nutrients on Waterways in Queensland, Australia, Frontiers of WWW Research and Development - APWeb 2006: Springer Berlin / Heidelberg) pp 11261135

ABS 20043222.0 - Population Projections, Australia, 2004 to 2101. Australian Bureau of Statistics)

Ahern K S, Ahern C R, Savige G M and Udy J W 2007 Mapping the distribution, biomass and tissue nutrient levels of a marine benthic cyanobacteria bloom (Lyngbya majuscula) Marine and Freshwater Research 58 883-904

Ahern K S, Udy J W and Pointon S M 2006 Investigating the potential for groundwater from different vegetation, soil and landuses to stimulate blooms of the cyanobacterium, Lyngbya majuscula, in coastal waters Marine and Freshwater Research 57 177-186

Ahmed B A, Matheny M E, Rice P L, Clarke J R and Ogunyemi O I 2009 A comparison of methods for assessing penetrating trauma on retrospective multi-center data Journal of Biomedical Informatics 42 308-316

Albert S, O'Neil J M, Udy J W, Ahern K S, O'Sullivan C M and Dennison W C 2005 Blooms of the cyanobacterium Lyngbya majuscula in coastal 
618

619

627

634

640

641

642

Queensland, Australia: disparate sites, common factors Marine Pollution Bulletin 51 428-437

Angeli D, De Leenheer P and Sontag E D 2007 A Petri net approach to the study of persistence in chemical reaction networks Mathematical Biosciences 210 598-618

Arquitt S and Johnstone R 2004 A scoping and consensus building model of a toxic blue-green algae bloom System Dynamics Review 20 179-198

Bednarski M, Cholewa W and Frid W 2004 Identification of sensitivities in Bayesian networks Engineering Applications of Artificial Intelligence 17 327-335

Borsuk M E, Reichert P, Peter A, Schager E and Burkhardt-Holm P 2006 Assessing the decline of brown trout (Salmo trutta) in Swiss rivers using a Bayesian probability network Ecological Modelling 192 224-244

Bromley J, Jackson N A, Clymer O J, Giacomello A M and Jensen F V 2005 The use of Hugin to develop Bayesian networks as an aid to integrated water resource planning Environmental Modelling \& Software 20231 242

Coupe VMH, van der Gaag L C and Habbema J D F 2000 Sensitivity analysis: an aid for belief-network quantification The Knowledge Engineering Review 15 215-232

Dennison W C and Abal E G 1999 Moreton Bay Study: A Scientific Basis for the Healthy Waterways: South East Queensland Regional Water Quality Management Strategy)

Dennison W C, O'Neil J M, Duffy E J, Oliver P E and Shaw G R 1999 Blooms of the cyanobacterium Lyngbya majuscula in coastal waters of 
643

644

645

646

648

652

653

654

655

656

657

658

659

660

661

662

663

664

665

666

667

Queensland, Australia Bulletin de I'Institut Oceanographique, Monaco

$19501-506$

eWater CRC 2007 E2 Catchment Modelling Toolkit.

Fielding F, Alston C, Dwyer M, Hamilton G, Johnson S, McVinish R, Peterson

N and Mengersen K 2007 LYNGBYA Task 2.3: Development of an Integrating Framework for the Lyngbya Research and Management Program 2005-2007 Bayesian Belief Networks. (Brisbane, Australia: Healthy Waterways Partnership) pp 1-39

Goss P J E and Peccoud J 1998 Quantitative Modeling of Stochastic Systems in Molecular Biology by Using Stochastic Petri Nets Proceedings of the National Academy of Sciences of the United States of America 95 $6750-6755$

Hamby D M 1994 A Review of Techniques for Parameter Sensitivity Analysis of Environmental Models Environmental Monitoring and Assessment

32 135-154

Hamilton G, McVinish R and Mengersen K 2007a Bayesian model identification and averaging for coastal algal bloom prediction.

Hamilton G, McVinish R and Mengersen K 2007b Bayesian model identification and averaging for coastal algal bloom prediction Ecological Applications in press

Hamilton G S, Fielding F, Chiffings A W, Hart B T, Johnstone R W and Mengersen K 2007c Investigating the Use of a Bayesian Network to Model the Risk of Lyngbya majuscula Bloom Initiation in Deception Bay, Queensland Human and Ecological Risk Assessment 13 12711279 
668 Hepler A B and Weir B S 2008 Object-oriented Bayesian networks for

669 paternity cases with allelic dependencies Forensic Science

$670 \quad$ International: Genetics 2 166-175

671 Hugin 2007 Hugin.

672 Janssens D, Wets G, Brijs T, Vanhoof K, Arentze T and Timmermans H 2006 673 Integrating Bayesian networks and decision trees in a sequential rule-

674 based transportation model European Journal of Operational Research

$675 \quad 17516-34$

676 Jensen F V and Nielsen T D 2007 Bayesian Networks and Decision Graphs:

677 Springer Science + Business Media, LLC)

678 Kjaerulff U 1995 dHugin - a computational system for dynamic time-sliced

679 Bayesian networks International Journal of Forecasting 11 89-111

680 Koller D and Pfeffer A 1997 Object-Oriented Bayesian Networks. In:

681 Thirteenth Annual Conference on Uncertainty in Artificial Intelligence

682 (UAI-97), (Providence, Rhode Island pp 302-313

683 Laskey K B 1995 Sensitivity Analysis for Probability Assessments in Bayesian

684 Networks IEEE Transactions on Systems, Man and Cybernetics 25

$685901-909$

686 Lauritzen S L, Dawid A P, Larsen B N and Leimer H G 1990 Independence

687 properties of directed Markov fields Networks 20 491-505

688 McCann R K, Marcot B G and Ellis R 2006 Bayesian belief networks:

689 applications in ecology and natural resource management1 Canadian

$690 \quad$ Journal of Forest Research 363053

$691 \quad$ Norsys 2007 Netica. 
692 Osborne N J, Shaw G R and Webb P M 2007 Health effects of recreational 693 exposure to Moreton Bay, Australia waters during a Lyngbya majuscula $694 \quad$ bloom Environment International 33 309-314

695 Osborne N J T, Webb P M and Shaw G R 2001 The toxins of Lyngbya 696 majuscula and their human and ecological health effects Environment $697 \quad$ International $27381-392$

698 Park M-H and Stenstrom M K 2008 Classifying environmentally significant 699 urban land uses with satellite imagery Journal of Environmental $700 \quad$ Management $86181-192$

701 Paul V J, Thacker R W, Banks K and Stjepko G 2005 Benthic cyanobacterial 702 bloom impacts the reefs of South (Broward County, USA) Coral Reefs 703

704 Pearl J 1988 Probabilistic Reasoning in Intelligent Systems (San Francisco, $705 \quad$ California: Morgan Kaufmann Publishers Inc)

706 Pollino C A, White A K and Hart B T 2007 Examination of conflicts and 707 improved strategies for the management of an endangered Eucalypt species using Bayesian networks Ecological Modelling 201 37-59

709 Saddo A, Letcher R A, Jakemana A J and Newham L T H 2005 A Bayesian

710 decision network approach for assessing the ecological impacts of

711 salinity management Mathematics and Computers in Simulation 69 $712 \quad 162-176$

713 Stielow S and Ballantine D L 2003 Benthic cyanobacterial, Micro-coleus 714 lyngbyaceus, blooms in shallow, inshore Puerto Rican seagrass 715 habitats, Caribbean Sea Harmful Algae 2 127-133 
716 Taroni F, Aitken C, Garbolino P and Biedermann A 2006 Bayesian Networks

717 and Probabilistic Inference in Forensic Science: John Wiley \& Sons, $718 \quad$ Ltd)

719 Uusitalo L 2007 Advantages and challenges of Bayesian networks in

720 environmental modelling Ecological Modelling 203 312-318

721 Watkinson A J, O'Neil J M and Dennison W C 2005 Ecophysiology of the

722 marine cyanobacterium, Lyngbya majuscula (Oscillatoriaceae) in

723 Moreton Bay, Australia Harmful Algae 4 697-715

724 Weber $\mathrm{P}$ and Jouffe L 2006 Complex system reliability modelling with Dynamic Object Oriented Bayesian Networks (DOOBN) Reliability Engineering \& System Safety 91 149-162

727 Wilson A G, Graves T L, Hamada M S and Reese C S 2006 Advances in Data 728 Combination, Analysis and Collection for System Reliability

$729 \quad$ Assessment Statistical Science 21 514-531 
732

733

734

735

736

737

738

739

740

741

742

743 744 slice

745

746

747

748

749

750

751

753

754

755

756

\section{Legends}

Figure 1: UML use case diagram of the conceptual processes in the Lyngbya bloom initiation Integrated Network

Figure 2: UML use case diagram of the processes for the Lyngbya bloom initiation DOOBN

Figure 3: UML activity diagram detailing the processes for the Lyngbya bloom initiation IBN

Figure 4: Science Network for Lyngbya initiation (Netica®)

Figure 5: Rainwater OOBN sub-network showing two output nodes,

Groundwater Amount and Land Run-off Load, which are then connected to the input nodes Prev Groundwater and Prev Land Run-off in the next time

Figure 6: Science OOBN sub-network

Figure 7: Five time slices forming the DOOBN for Lyngbya bloom initiation

Figure 8: Expanded sub-network instances in Hugin®, showing the interface nodes for each instance. The input and output nodes are represented here as ellipses with broken and solid lines, respectively. Also evident are the directed links between the sub-network instances of the same and the next time slice, so that information from one time slice can flow into the next time slice.

Figure 9: Extract of the Management Network for Mellum Creek Subcatchment, a visual representation of the sub-catchment, showing point and diffuse sources of nutrients. The inset shows the complete Management Network

Figure 10: Probability of Lyngbya bloom initiation 
757

758 Table 1: Conditional probability table for Bottom Current Climate node with

759 states Low and High and parent nodes Wind Direction (states North, SE and

760 Other), Wind Speed (states Low and High) and Tide (states Spring and

761 Neap). These nodes, their states, probabilities and relationships are visible in

762 the Bayesian network in figure 4

763

\begin{tabular}{ccccc}
\hline $\begin{array}{c}\text { Wind } \\
\text { Direction }\end{array}$ & $\begin{array}{c}\text { Wind } \\
\text { Speed }\end{array}$ & Tide & Low & High \\
\hline North & Low & Spring & 0.33 & 0.67 \\
North & Low & Neap & 0.61 & 0.39 \\
North & High & Spring & 0.43 & 0.57 \\
North & High & Neap & 0.54 & 0.46 \\
SE & Low & Spring & 0.42 & 0.58 \\
SE & Low & Neap & 0.58 & 0.42 \\
SE & High & Spring & 0.37 & 0.63 \\
SE & High & Neap & 0.59 & 0.41 \\
Other & Low & Spring & 0.39 & 0.61 \\
Other & Low & Neap & 0.59 & 0.41 \\
Other & High & Spring & 0.43 & 0.57 \\
Other & High & Neap & 0.50 & 0.50 \\
\hline
\end{tabular}


766 Table 2: Changes to the probability of Lyngbya bloom initiation for key

767 factors. All possible states for each of the nodes were assessed individually to

768 ascertain the delta effect it had on the probability of a Lyngbya bloom

769 initiation.

770

771

\begin{tabular}{lc}
\hline \multicolumn{1}{c}{ Factor } & $\begin{array}{c}\text { Change in P(Bloom) } \\
(\%)\end{array}$ \\
\hline Available Nutrient Pool & 77 \\
Bottom Current Climate & 28 \\
Sediment Nutrient Climate & 17 \\
Dissolved Fe & 16 \\
Dissolved P & 15 \\
Light Climate & 14 \\
Temperature & 14 \\
\hline
\end{tabular}


Table 3: Point and diffuse sources contributing nutrients to Deception Bay

774

\begin{tabular}{lccccc}
\hline Source & $\begin{array}{c}\text { Point(P) or } \\
\text { Diffuse (D) }\end{array}$ & Nitrogen & Phosphorous & Iron & Organics \\
\hline Aquaculture & $\mathrm{P}$ & $\mathrm{X}$ & $\mathrm{X}$ & & \\
Composting & $\mathrm{P}$ & $\mathrm{X}$ & $\mathrm{X}$ & & \\
Onsite Sewage & $\mathrm{P}$ & $\mathrm{X}$ & $\mathrm{X}$ & & \\
Poultry & $\mathrm{P}$ & $\mathrm{X}$ & $\mathrm{X}$ & $\mathrm{X}$ & \\
Waste Disposal & $\mathrm{P}$ & $\mathrm{X}$ & $\mathrm{X}$ & $\mathrm{X}$ & \\
Waste Water Treatment Plant & $\mathrm{P}$ & $\mathrm{X}$ & $\mathrm{X}$ & & \\
Agriculture & $\mathrm{D}$ & $\mathrm{X}$ & $\mathrm{X}$ & $\mathrm{X}$ & $\mathrm{X}$ \\
Artificial Development & $\mathrm{D}$ & $\mathrm{X}$ & $\mathrm{X}$ & & \\
Developing \& Clearing & $\mathrm{D}$ & $\mathrm{X}$ & $\mathrm{X}$ & $\mathrm{X}$ & $\mathrm{X}$ \\
Extractive & $\mathrm{D}$ & $\mathrm{X}$ & $\mathrm{X}$ & & \\
Forestry & $\mathrm{D}$ & $\mathrm{X}$ & $\mathrm{X}$ & $\mathrm{X}$ & $\mathrm{X}$ \\
Grazing & $\mathrm{D}$ & $\mathrm{X}$ & $\mathrm{X}$ & & \\
Natural Vegetation & $\mathrm{D}$ & $\mathrm{X}$ & $\mathrm{X}$ & & $\mathrm{X}$ \\
Stormwater & $\mathrm{D}$ & $\mathrm{X}$ & $\mathrm{X}$ & & \\
\hline
\end{tabular}




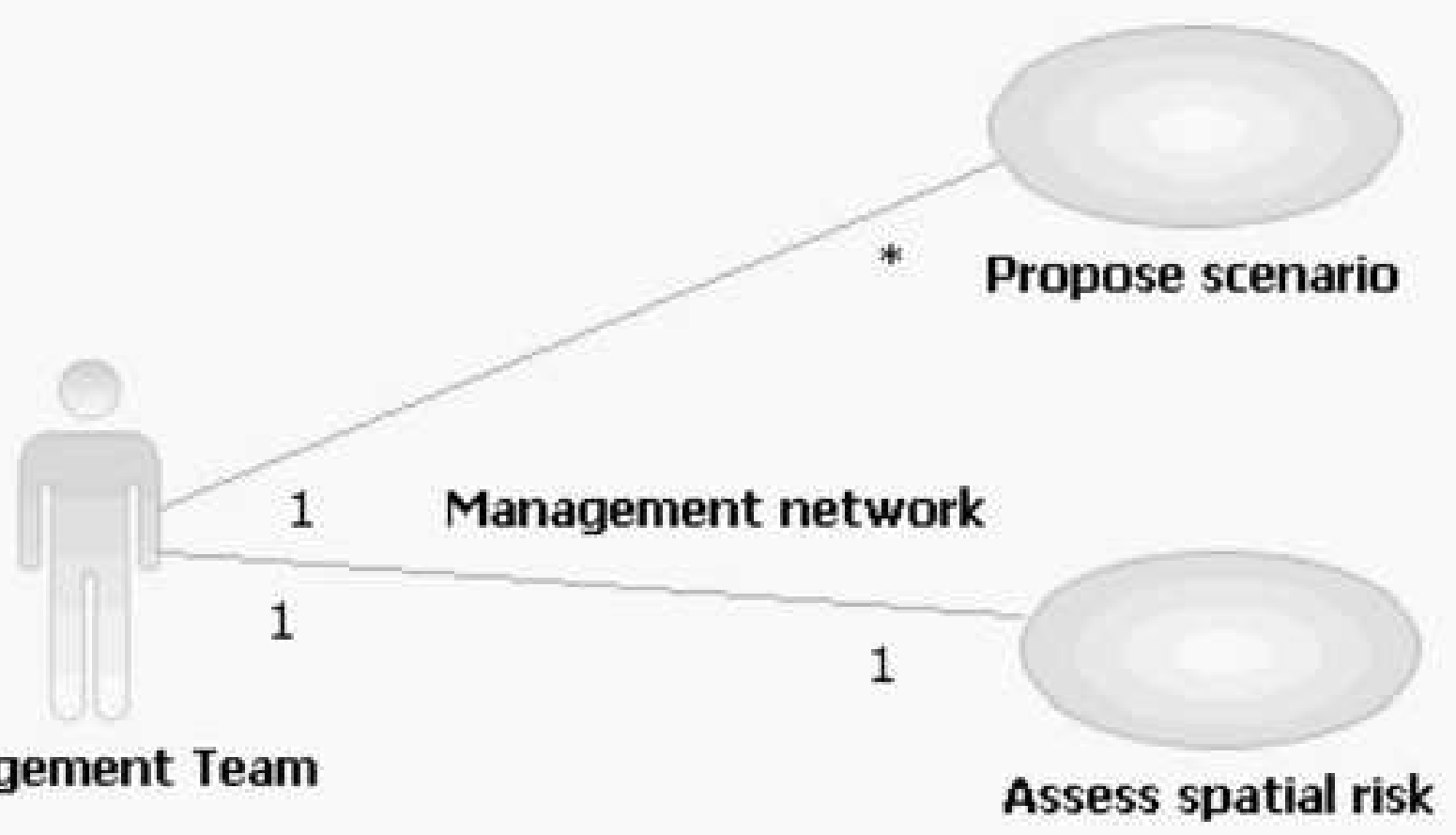

Management Team

Assess spatial risk

E2 Catchment model

1 Simulate actions

Ecological Modeller

Update Science BN 


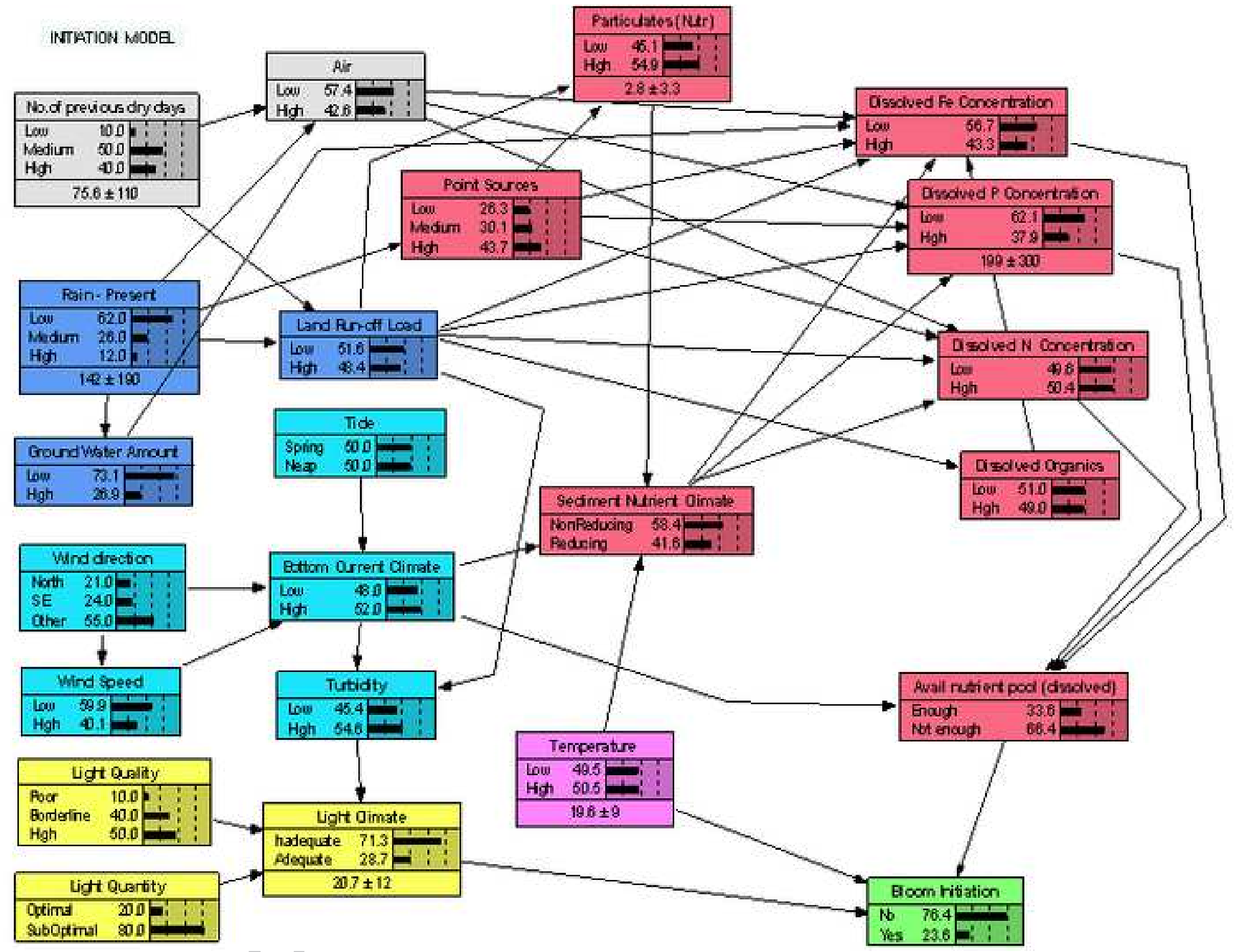




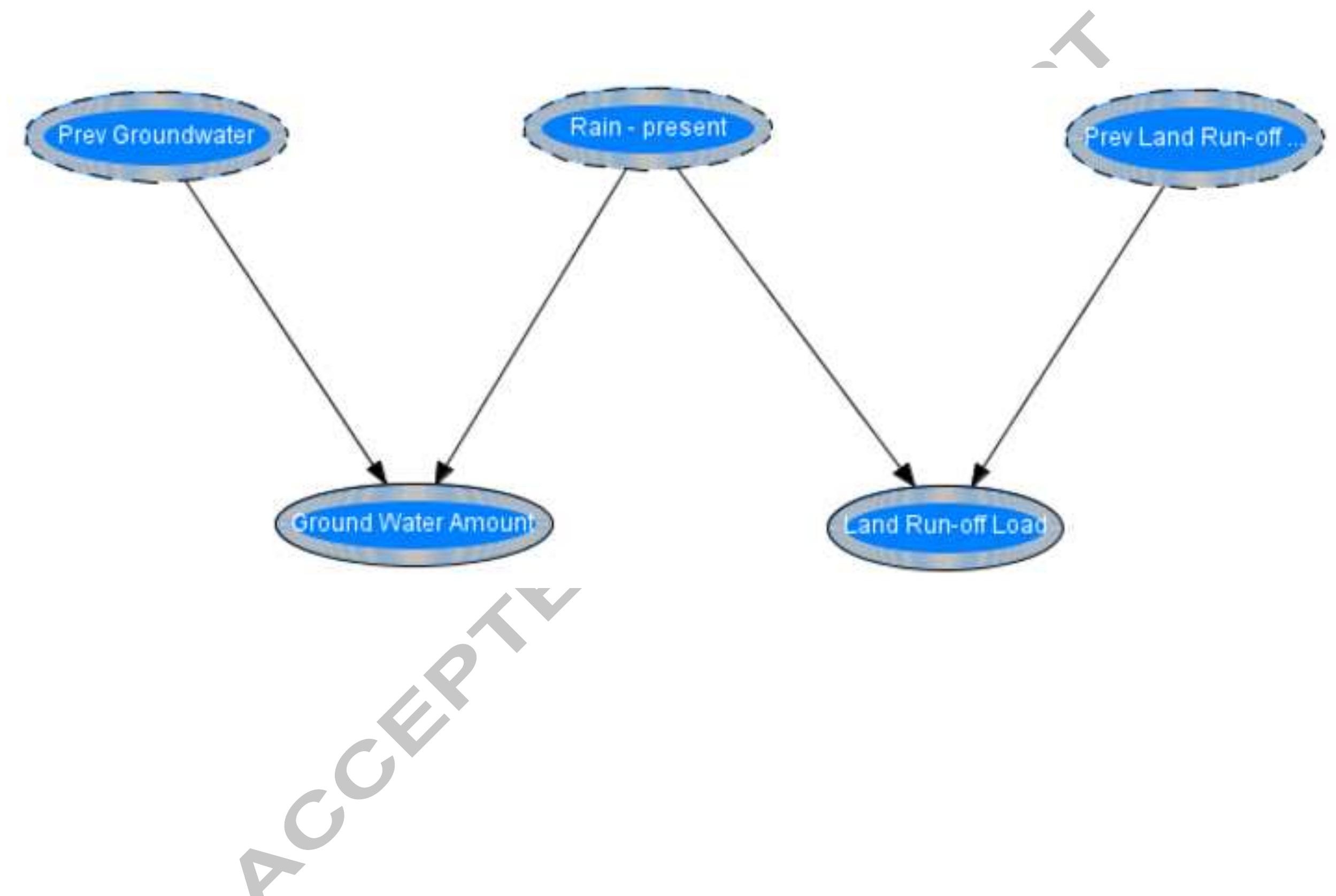




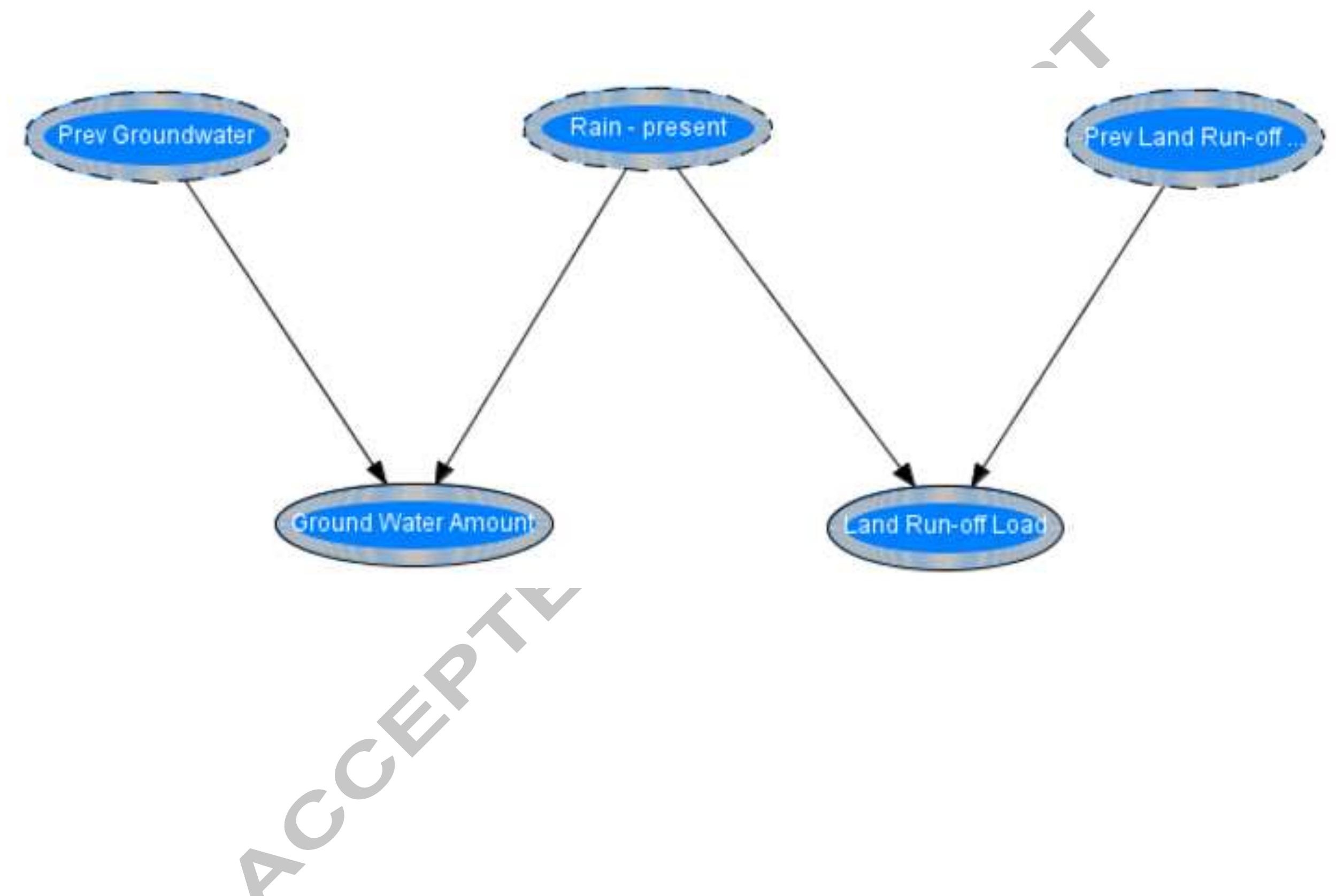




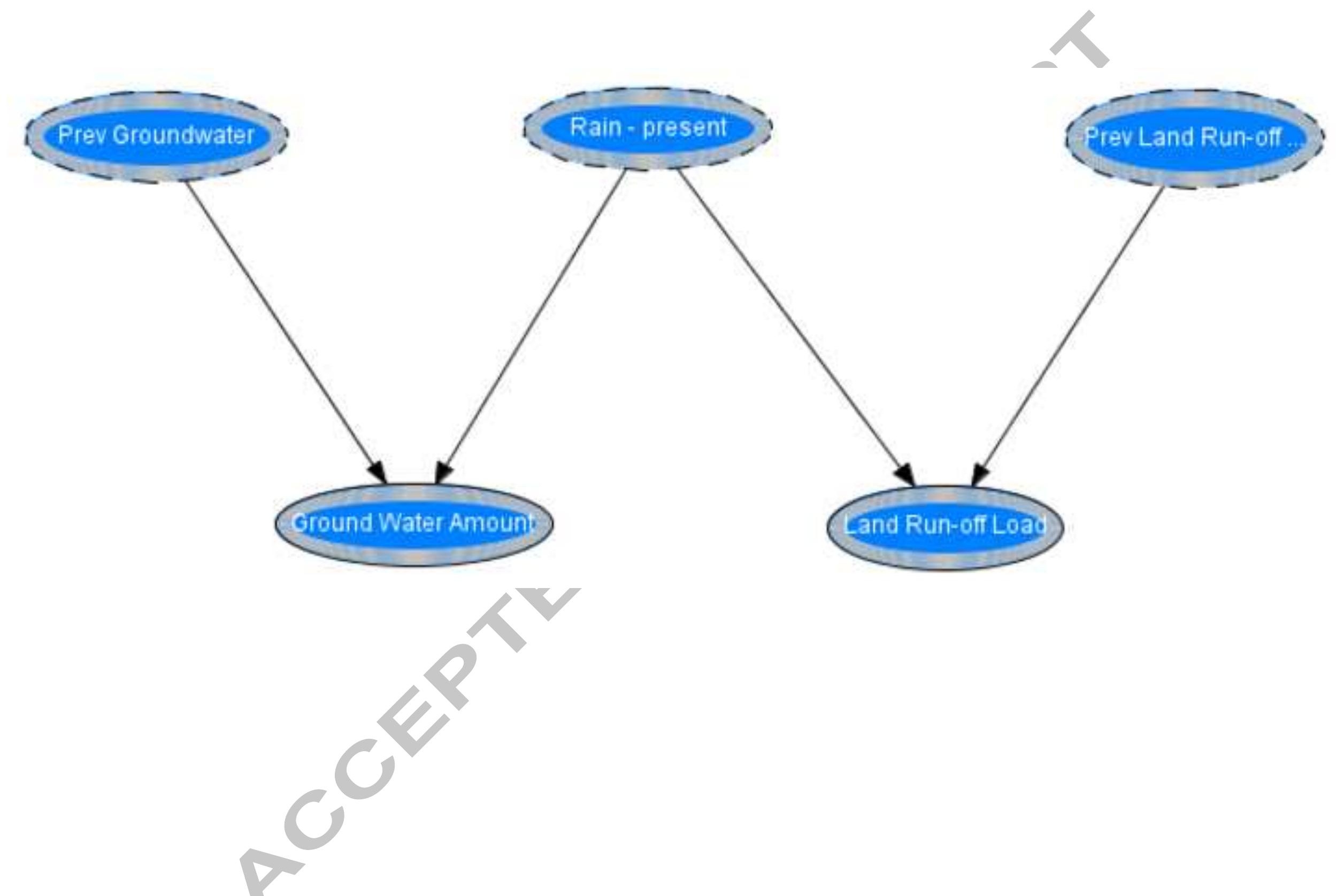




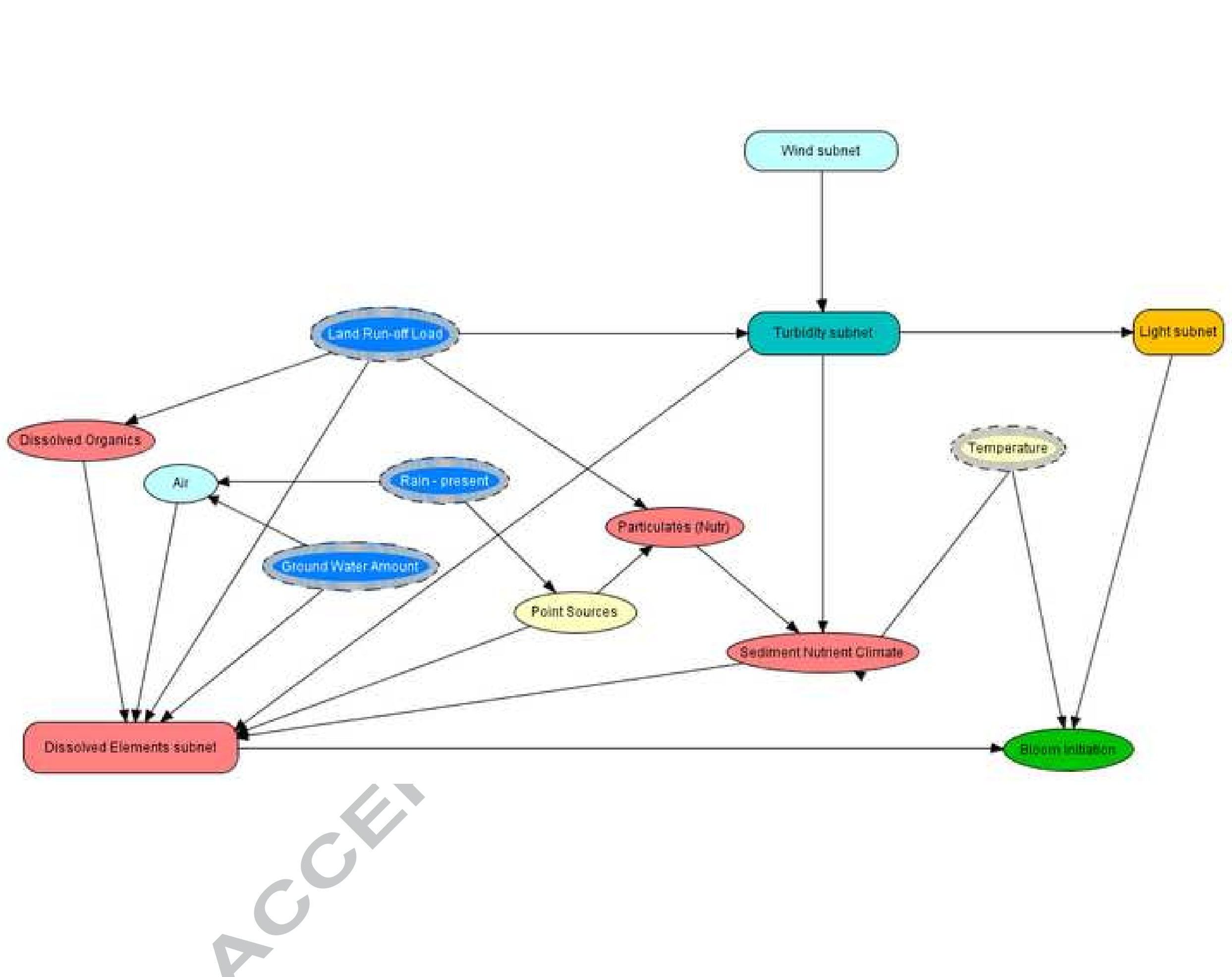




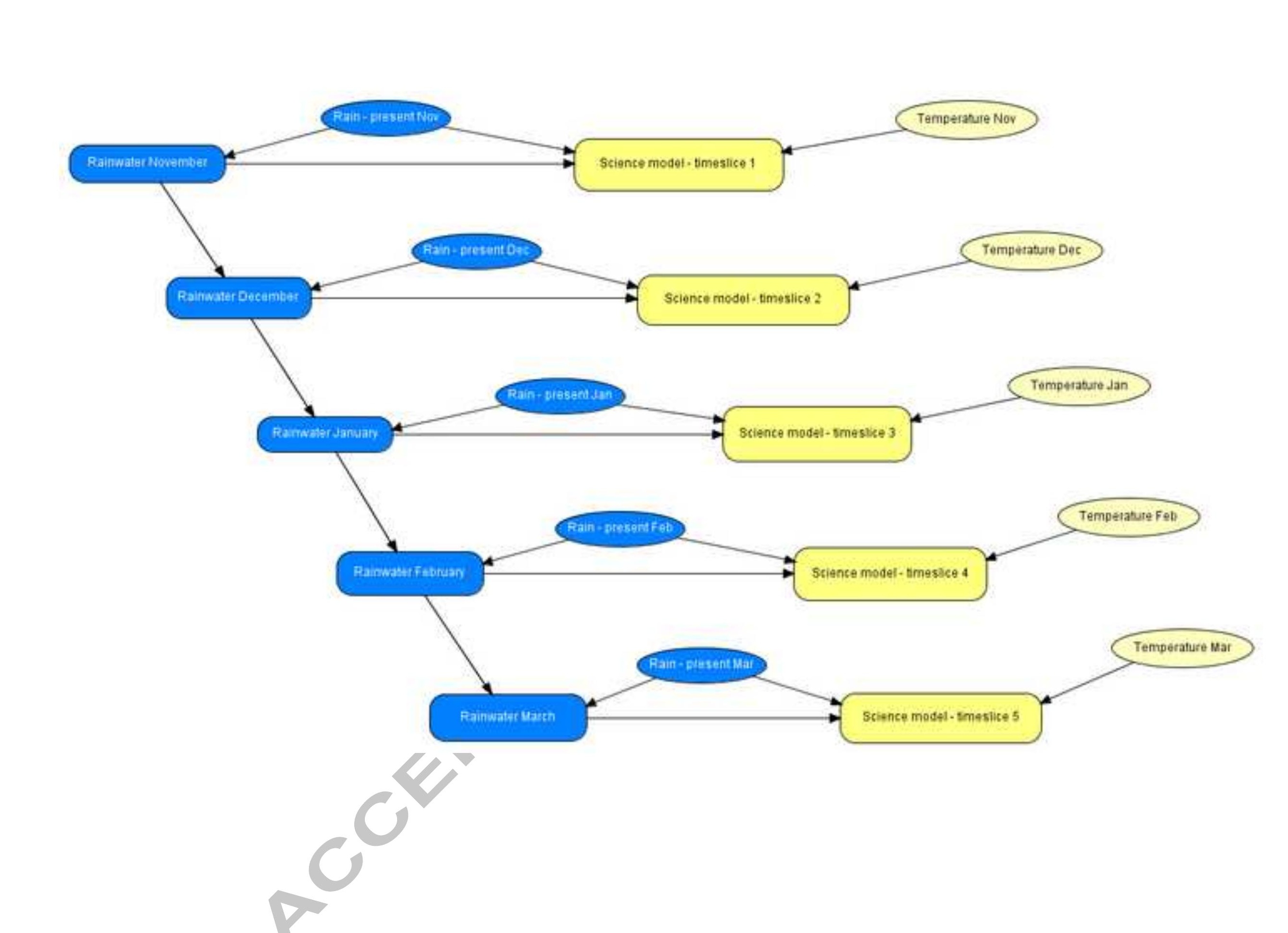

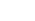

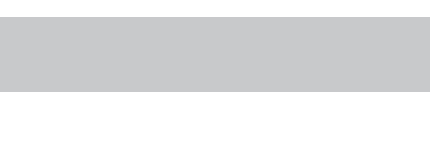

.
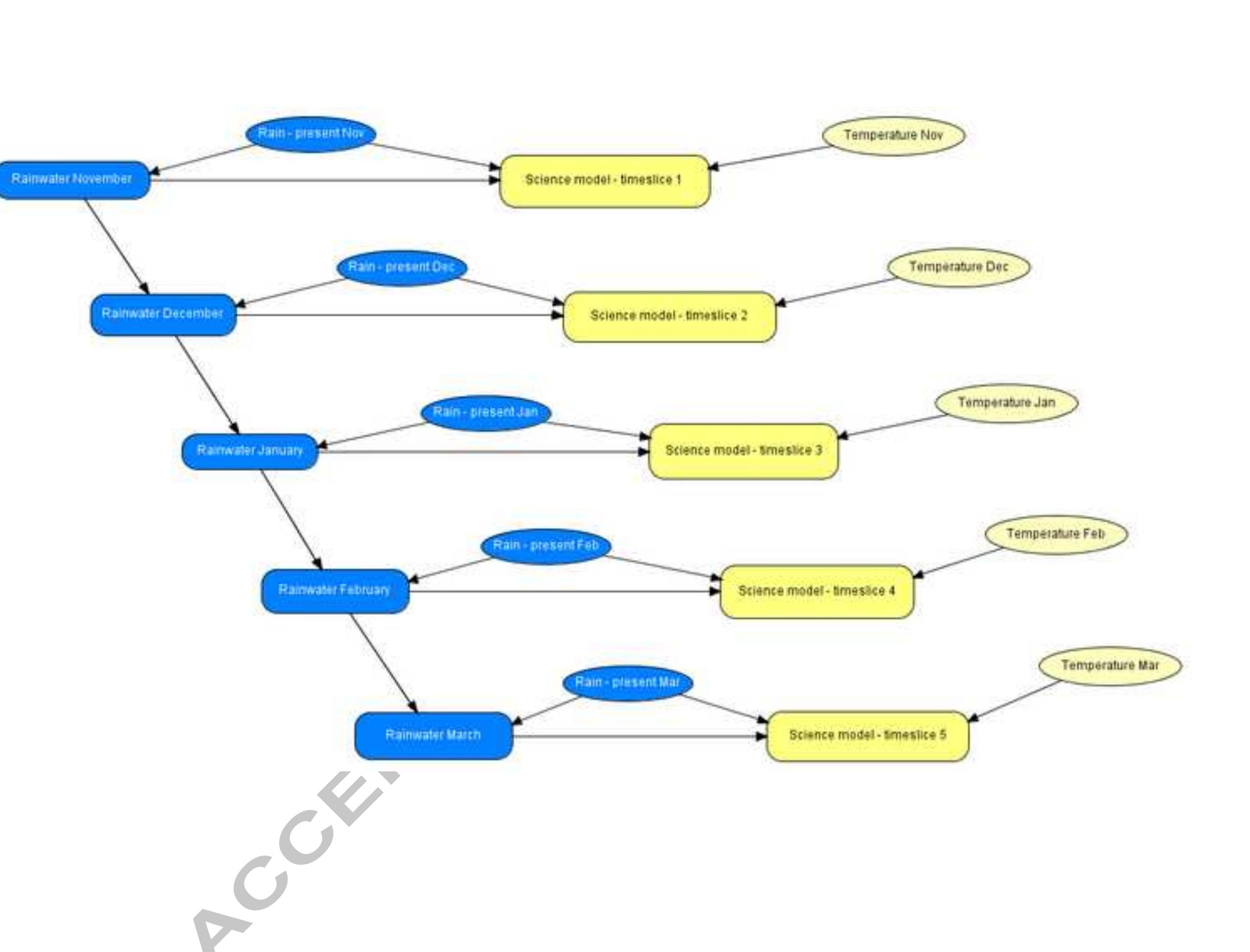

, . 


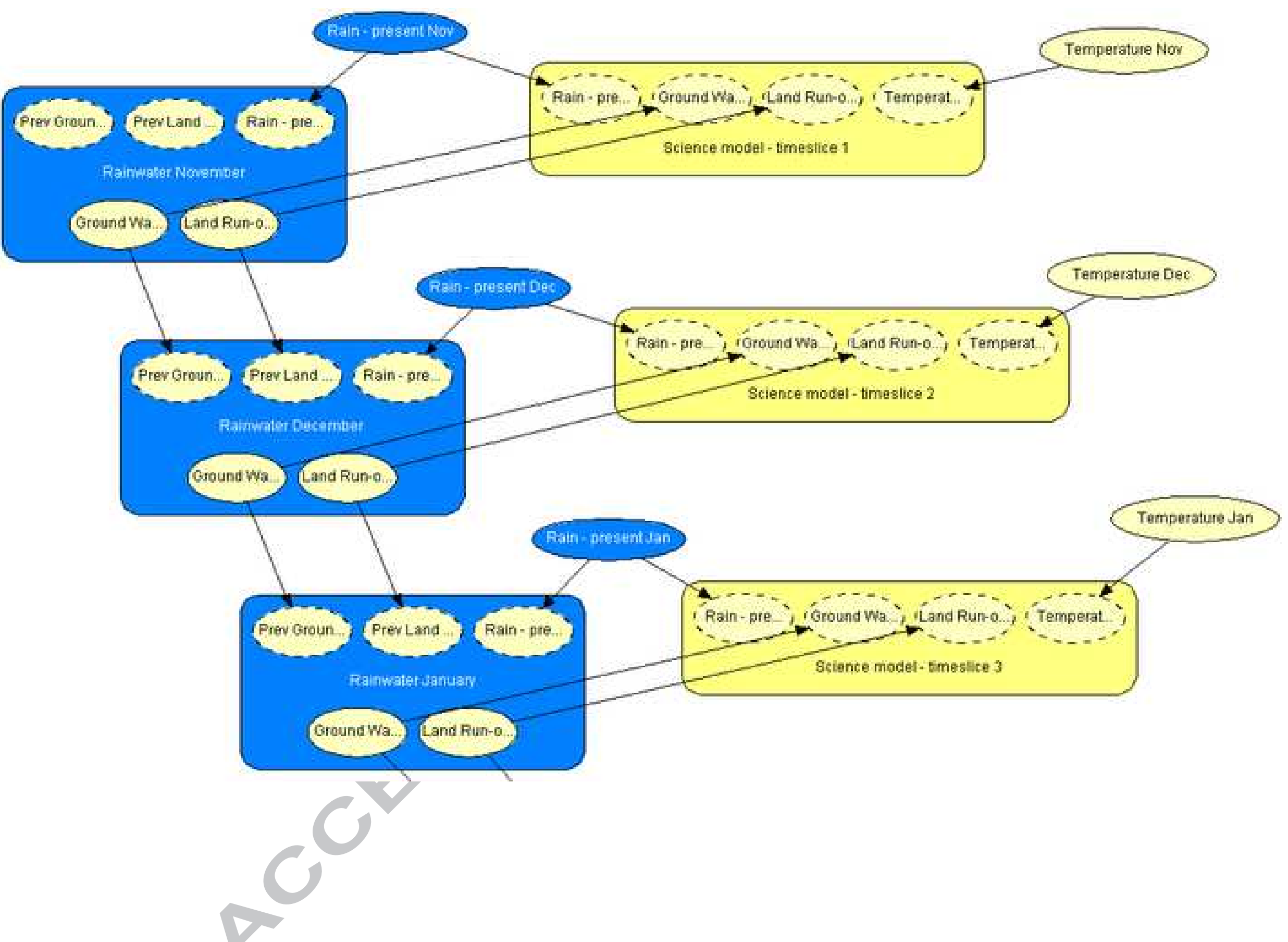




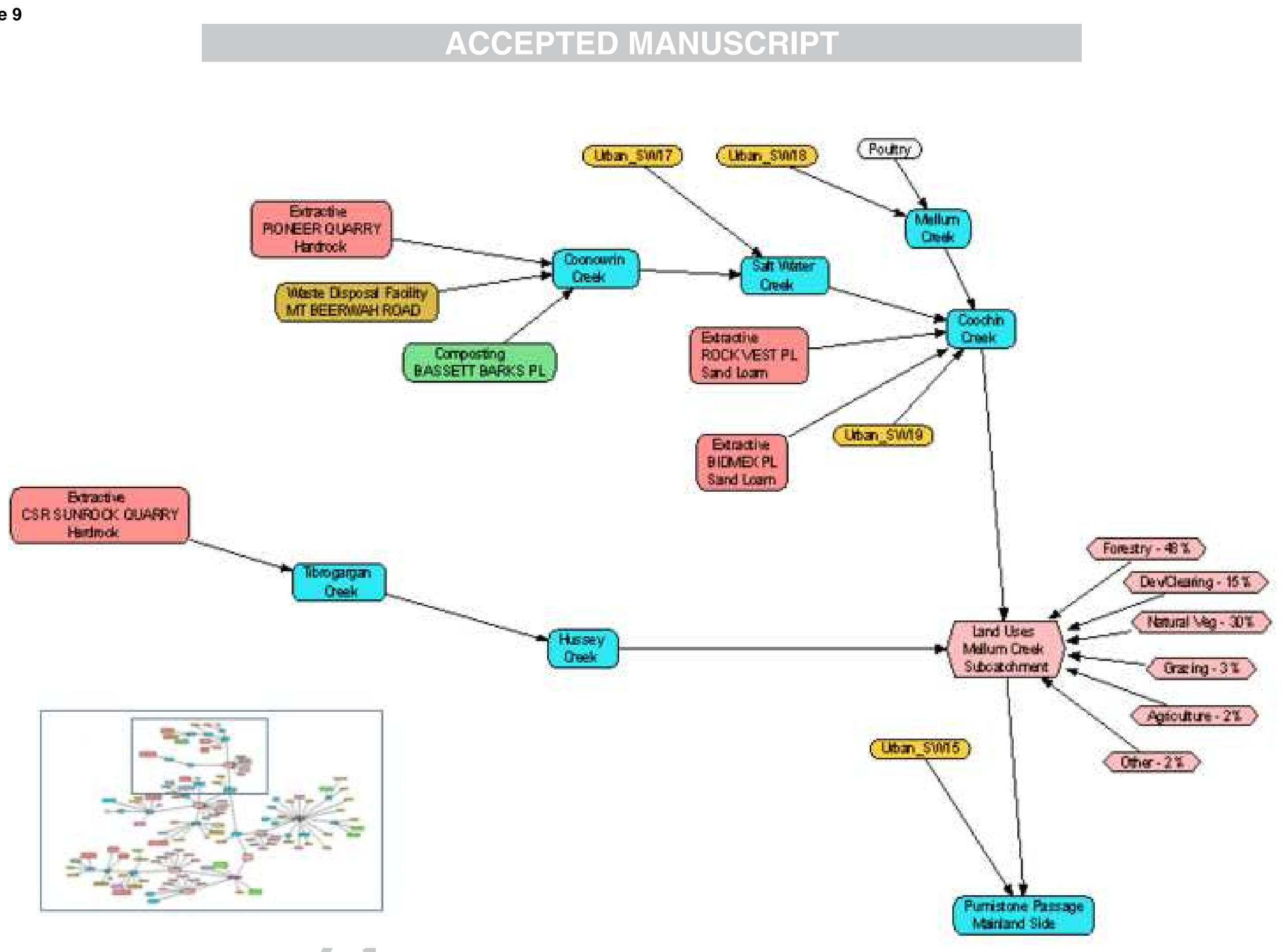




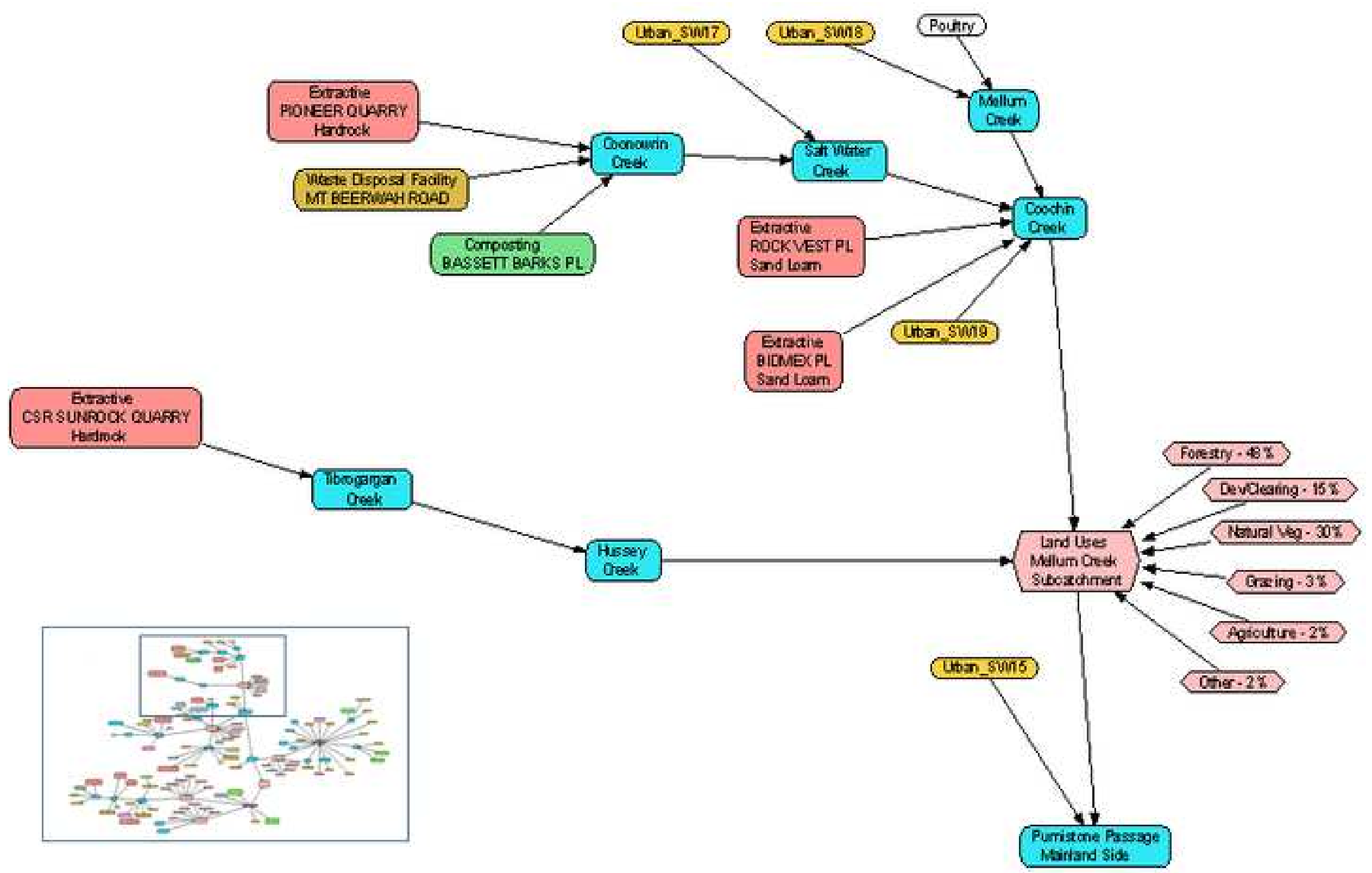

Exactie
PONEERQUAR

Hatook

Reste Disposa facility

Composting

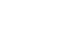




\section{ACCEPTED MANUSCRIPT}

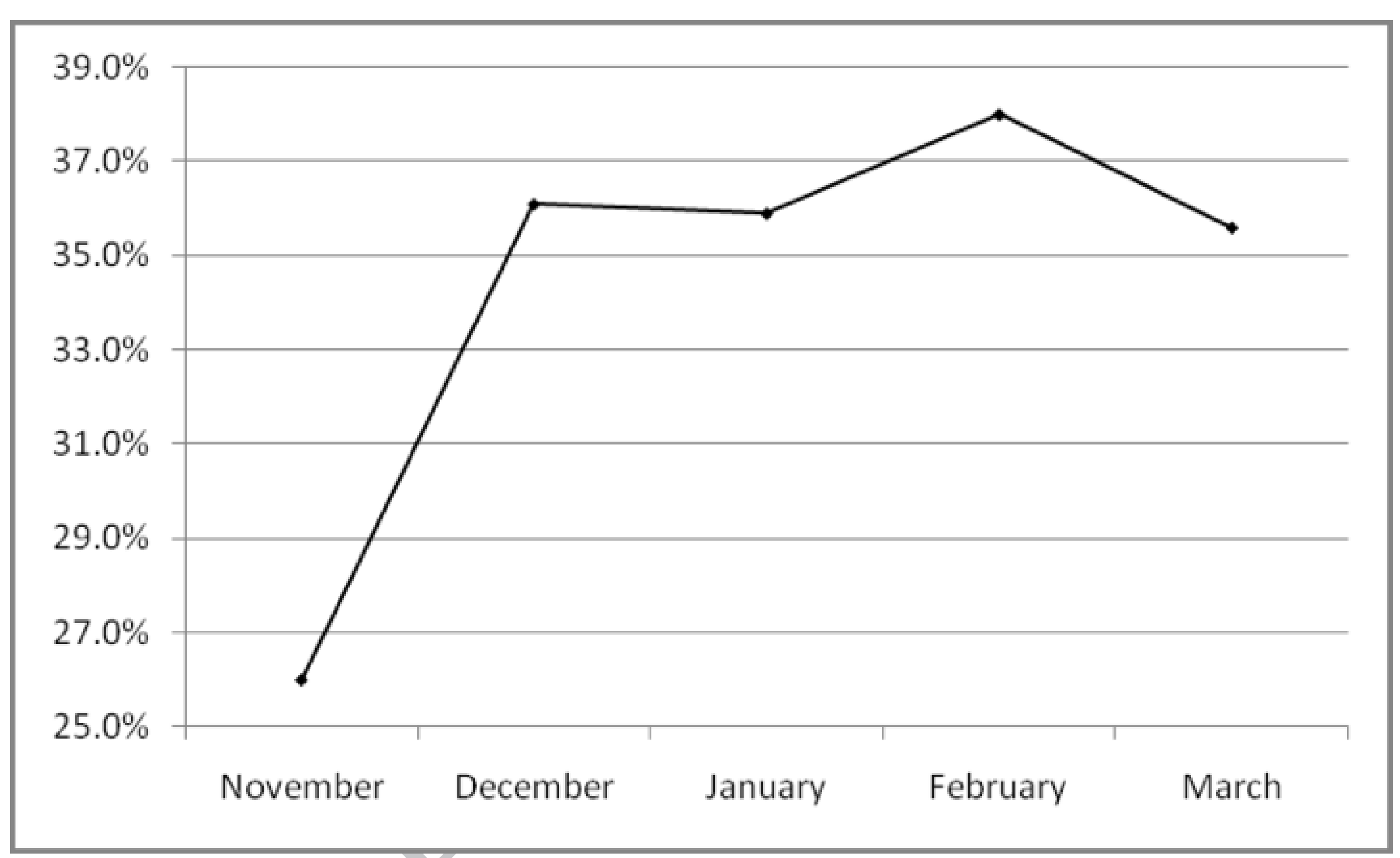

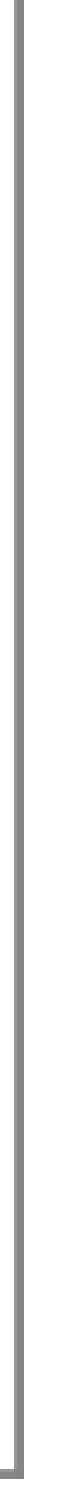




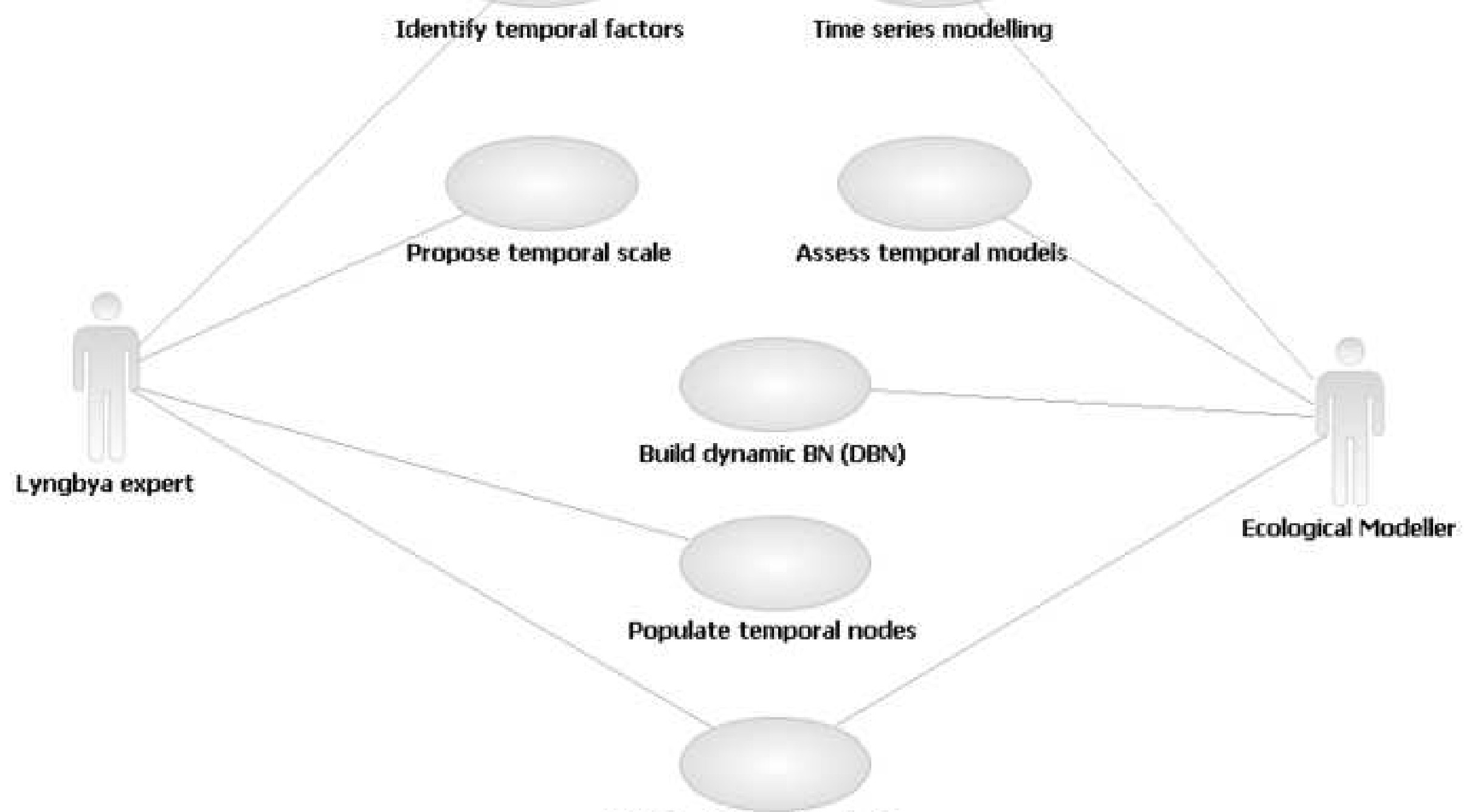

DBN Testing and evaluation 

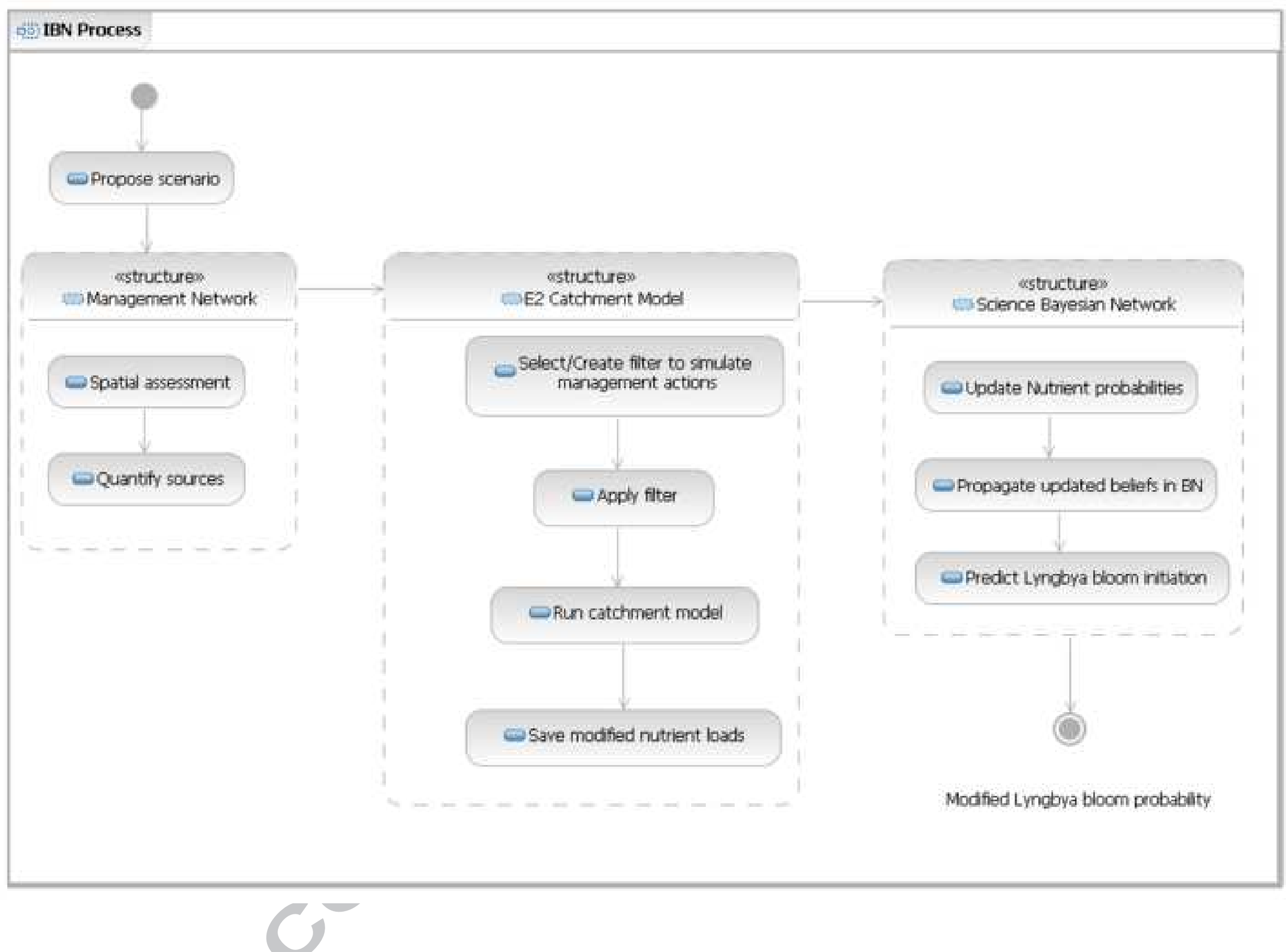